improving the employment prospects of people with chronic health problems would maintain their living standards, which is an important task in itself, and in addition contribute directly to better health and wellbeing.

ESPEN DAHL

Research director

Institute for Applied Social Science,

$\mathrm{Pb} 2947$ Tøyen,

0608 Oslo,

Norway

1 Townsend P, Davidson N, eds. Inequalities in health. The Black report. Harmondsworth: Penguin, 1982.

2 Dutton DB, Levine S. Socieconomic status and health: Overview, methodological critique, and reformulation. In Bunker JP, Gomby DS, Kehrer BH. Pathways to health. The role of social factors. Menlo Park, CA: Henry J Kaiser Family Foundation, 1989.
3 Macintyre S, West P. Lack of class variation in health in adolescence: an artefact of an occupational measure of social class? Soc Sci Med 1991;32:395-402.

4 Bartley M, Owen C. Relation between socioeconomic status, employment, and health during economic change, 1973-93. BMY 1996;313:445-9.

5 Power C, Matthews S, Manor O. Inequalities in self rated health in the 1958 birth cohort: lifetime social circumstances or social mobility? BMF 1996;313:449-53.

Carpenter LM. Some obervations on the healthy worker effect. Br f Ind Med 1987;44:289-91.

7 Carpenter LM. Some observations on the healthy worker effect. Brf ind Med 1987;44:289-91. the health selection debate. European Sociological Review 1991;7:147-61. A contribution the health selection deba Bupean Sociological Review 1991;7:147-61.

.

9 Blane D, Smith GD, Bartley M. Social selection: what does it contribute to social class differences in health? Sociology of Health and Illness 1993;15:1-15.

10 West P. Rethinking the health selection explanation for health inequalities. Soc Sci Med 1991;32:373-84.

1 Dohrenwend BP, Itzhak L, Shrout PE, Schwartz S, Naveh G, Link BG, et al. Socioeconomic status and psychiatric disorders: the causation-selection issue. Science 1992;255:946-52.

12 Dahl E. Social inequality in health-the role of the healthy worker effect. Soc Sci Med 1993;36:1077-86.

13 Elstad JI. Employment status and women's health-exploring the dynamics. Acta Sociologica 1995;389:231-49.

14 Esping-Andersen G. The three worlds of welfare capitalism. Cambridge: Polity Press, 1990.

\title{
The future of epidemiology
}

\author{
It's bright, but epidemiology and publicity can be a dangerous mix
}

Few can challenge the assertion that epidemiology has been central in the control of infectious diseases, nor that it has contributed more than any other discipline in the identification of causes of cardiovascular diseases (from the classic to the more recently identified) ${ }^{12}$ and several forms of cancer (from tobacco smoking and occupational carcinogens to several infectious agents). ${ }^{3-5}$ However, concern has recently arisen that epidemiology has either exhausted its potential or, worse, is generating conflicting results that confuse the public and disorient policy makers.

The argument about stagnation is hardly justified. The clarification of the role of blood lipids and the documentation of the effects of aspirin, ethanol, homocysteine, and factor $V$ Leiden mutation are major recent breakthroughs in cardiovascular epidemiology, as is the identification of hepatitis viruses $B$ and $C$ and certain strains of human papillomavirus as definitive human carcinogens. Even a result that has been so consistent as to become boring - the protection provided by vegetables and fruits against several forms of cancer ${ }^{6}$-was not universally accepted 20 years ago.

More often, epidemiology has been indicted for rousing unsubstantiated fears about everyday exposures, through studies that are subsequently challenged by other epidemiological investigations. In a widely publicised special news report in Science Gary Taubes wrote that "the news about health risks comes thick and fast these days, and it seems almost constitutionally contradictory." The article points out that for just a single disease, breast cancer, there have been conflicting reports in major journals during the past year about whether magnetic fields, dicophane (DDT), and abortions increase the risk and whether breast feeding reduces the risk. There are several reasons why epidemiological results cannot always be expected to converge. Epidemiological studies are undertaken in different populations and under different conditions; a different set of background variables that can interact with the main exposures under investigation would generate divergent findings. Moreover, epidemiology is, as a rule, non-experimental and this fact alone increases the margin of error on account of residual confounding and subtle biases. Nevertheless, conflicting findings are no more common in epidemiology than in animal research or clinical investigations.

The issue is really that epidemiological findings and epidemiological contradictions are widely publicised, whereas this is not true of animal studies or other types of experimental research. It is unavoidable that the general public is more interested in what may happen to humans than in what may happen to a particular strain of mice or a certain laboratory system. Whether publicity is conducive to good science is debatable, but this is perhaps besides the point: a free press is an integral part of democracy, and it is predictable that whatever attracts the interest of the public will be reported by the media courtesy of journalists, authors, or even editors. Some people are concerned that the publicity surrounding contradictory reports may reduce the credibility of epidemiology, or even of science in general. If this were to make people more sceptical and more critical it would be a welcome development, since it would imply that the general public shares the mindset of epidemiologists themselves. The aim of epidemiology is to decipher nature with respect to human health and disease, and no one should underestimate the complexities of epidemiological research.

What is the future of epidemiology? The subject is likely to expand and flourish, as witnessed by the emergence of several subsidiary specialties like clinical epidemiology, behavioural epidemiology, and molecular epidemiology. ${ }^{8}$ However, practitioners of the discipline and consumers of epidemiological results should always keep in mind the limitations of epidemiological investigations. ${ }^{9}$ A simple principle should guide aetiological inferences in epidemiology: a sharp relative risk gradient can be considered to indicate a causal relation even in the absence of an adequate biological explanation, but weak empirical associations indicate a causal relation only when the supporting biological evidence is overwhelming. ${ }^{10}$

What will be the main focus areas of epidemiology in the future? Those who believe that there is no more room for innovation should be reminded of the fears expressed in the previous century that composition of music was approaching its limits. Modern music continues to thrive as modern epidemiology is likely to, even though both fields have their detractors. Moreover, epidemiology will benefit from technological advances like any other science. This has often happened in the past, and recently causes of cancers of the liver and uterine cervix were identified after the development of laboratory procedures for detecting chronic infection by the responsible viral agents. ${ }^{4}$ There will also be an increasing emphasis on specificity through large studies that will allow reliable distinction between genuine and false positive results. Clinical epidemiology is likely to improve the way clinical medicine and health services research are defined, implemented, and evaluated. As more and more genes that predispose to disease are discovered there will be an urgent need to identify exogenous factors that interact with these genes in the occurrence of human disease. Finally, conceptual shifts-for example, focusing on early life events-may enrich future epidemiological research, and theoretical developments may contribute to the epidemiologi- 
cal resolution of major enigmas, such as the largely unexplained differences in morbidity and mortality across socioeconomic groups. ${ }^{11}$

As I wrote in a letter to Science in response to Gary Taubes's article: " "It could be said for epidemiology, with respect to disease etiology and prevention, what is frequently said about democracy as a system of government: they both have many problems and weaknesses, but they still represent the best available approach for the achievement of their respective objectives."12

DIMITRIOS TRICHOPOULOS

Professor

Department of Epidemiology,

Harvard School of Public Health,

Boston, MA 02115,

USA
1 Stampfer MJ, Malinow MR. Can lowering homocysteine levels reduce cardiovascular risk? [editorial]. N Engl f Med 1995;332:328-9.

2 Vanderbroucke JP, Koster T, Biet E, Reitsma PH, Bertina RM, Rosendaal FR. Increased risk of venous thrombosis in oral-contraceptive users who are carriers of factor $\mathrm{V}$ Leiden mutation. Lancet 1994;344:1453-7.

3 Overall evaluations of carcinogenicity: an updating of IARC monographs from volumes 1-42. IARC Monogr Eval Carcinog Risks Hum Suppl 1987;7.

Hepatitis viruses. LARC Monogr Eval Carcinog Risks Hum 1994;59.

4 Hepatitis viruses. LARC Monogr Eval Carcinog Risks Hum 1994;59.

5 Human papillomaviruses. LARC Monogr Eval Carcinog Risks Hum 1995;64. Control 1996;7:178-80.

Control 1996;7:178-80.
Taubes G. Epidemiology faces its limits. Science 1995;269:164-9.

7 Taubes G. Epidemiology faces its limits. Science 1995;269:164-9.

9 MacMahon B. Strengths and limitations of epidemiology. In: The National Research Council in 1979. Current issues and studies. Washington, DC: National Academy of Sciences, 1979:91-104.

10 MacMahon B, Trichopoulos D. Epidemiology: principles and methods. Boston: Little, Brown, 1996.

11 Marmot MG, Shipley MJ, Tose G. Inequalities in health -specific explanations of a general pattern? Lancet 1984;i:1003-6.

12 Trichopoulos D. The discipline of epidemiology [letter]. Science 1995;269:1326.

\title{
Treating hypertension: the evidence from clinical trials
}

\author{
Aim for treated diastolic pressure levels of $80-90 \mathrm{~mm} \mathrm{Hg}$
}

Survey data show that most elderly people have hypertension. ${ }^{1}$ Guidelines for treating hypertension in elderly people have evolved as data from observational studies and clinical trials have become available. As recently as 10 years ago it was unclear whether the benefits of drug treatment in elderly people outweighed the risks. Doctors were cautioned about the side effects of antihypertensive drugs and were advised to treat only those elderly patients with the highest blood pressures. Some expert panels recommended drug treatment for healthy 65-74 year old patients only when blood pressure levels reached $200 / 100 \mathrm{~mm} \mathrm{Hg}$ or greater, and for healthy patients over 75 years only when diastolic blood pressure levels reached $120 \mathrm{~mm} \mathrm{Hg}$ or greater. ${ }^{2}$ The decision to treat elderly patients with smaller rises in blood pressure was left to the discretion of the individual doctor. ${ }^{2}$

Meta-analyses of the clinical trials of antihypertensive drug treatment in elderly people have been published recently, ${ }^{3-5}$ and some of the uncertainties that faced expert panels 10 years ago have been resolved. By pooling the results of 13 clinical trials that together enrolled over 16000 elderly participants from Europe, Australia, the United States, and Japan, these meta-analyses found that treating hypertension in elderly people significantly decreased morbidity and mortality due to cardiovascular disease as well as all cause mortality. Over about five years of follow up, antihypertensive drug treatment was found to lower the risk of stroke by $35 \%$ and the risk of coronary events by $20 \%$. Drug treatment of hypertension in elderly people also resulted in about a $15 \%$ reduction in all cause mortality. For patients over 80 years old, the benefits of lowering blood pressure were less clear. On the basis of the results of these studies, elderly patients with hypertension should be treated above a threshold of $160 / 90 \mathrm{~mm} \mathrm{Hg}$.

The evidence from clinical trials regarding the benefits of treating hypertension among middle aged patients (blood pressure levels of $140 / 90 \mathrm{~mm} \mathrm{Hg}$ or greater) also seems clear: drug treatment lowers the risk of cardiovascular morbidity and mortality. ${ }^{4}$ Because observational studies indicate that young adults with hypertension are at considerably increased risk of coronary heart disease when followed over several decades, some expert panels recommend that screening for hypertension should begin at age $21 .{ }^{6}$ However, there are few clinical trial data regarding the long term effectiveness of antihypertensive drug treatment in young adults (under 30 years of age). In young adults with mildly raised blood pressure and in whom secondary causes of hypertension have been excluded, non-pharmacological treatment is preferred. For young adults with diastolic blood pressure levels greater than $100 \mathrm{~mm} \mathrm{Hg}$ or with other risk factors that increase overall cardiovascular risk, drug treatment should be considered to prevent target organ damage.

Clinical trial data support the recommendation that patients with hypertension be advised to make lifestyle changes to lower their blood pressure, including weight reduction, increased exercise, dietary salt restriction (to less than 5-6 g/day), and alcohol restriction (to less than two or three drinks a day) ${ }^{7}$ However, for many patients who do not respond adequately or who are unable to comply with such lifestyle modifications, drug treatment will be necessary. For most hypertensive patients, treatment may begin with either a $\beta$ adrenergic blocker (in younger patients) or a low dose thiazide diuretic (in older patients). ${ }^{8}$ These drugs have been used for several decades, have been shown to be safe and effective, and are the only drugs proved to reduce cardiovascular morbidity and mortality.

How far to lower raised blood pressure to achieve maximum benefit is unclear. In this week's issue of the $B M \mathcal{F}$, Merlo et al report the results from a population based cohort study in $\mathbf{4 8 4}$ men ( $p$ 457). ${ }^{9}$ They found that the incidence of ischaemic cardiac events was increased in those taking antihypertensive medication and that it was increased fourfold in those with diastolic blood pressure levels below $90 \mathrm{~mm} \mathrm{Hg}$, even after adjustment for confounding. Results from other observational studies and clinical trials in middle aged and elderly patients have indicated that diastolic blood pressure levels lower than $85 \mathrm{~mm} \mathrm{Hg}$ are associated with an increased risk for coronary heart disease. ${ }^{11}{ }^{11}$ However, one meta-analysis of clinical trial data was unable to detect such an association. ${ }^{12}$ Until it is clear whether low diastolic pressures levels are a cause or a consequence of coronary heart disease, it seems prudent to aim for treated diastolic pressure between 80 and $90 \mathrm{~mm} \mathrm{Hg}$.

Although substantial progress has been made in detecting and treating patients with hypertension, recent survey data from the United States indicate that there is considerable room for improvement: about $35 \%$ of people with hypertension go undetected, $50 \%$ of those detected are not taking medication, and $80 \%$ of those taking antihypertensive medication still have blood pressures over $140 / 90 \mathrm{~mm} \mathrm{Hg} .{ }^{1}$ On the basis of the clinical trial evidence, the effective control of hypertension in middle aged and elderly patients (and possibly in young adults) can be expected to result in an accelerated decline in the incidence of stroke, myocardial infarction, and the rate of cardiovascular death.

JOEL A SIMON Assistant professor

Departments of Medicine, Epidemiology, and Biostatistics,

University of California,

San Francisco, CA 94105, USA 